\title{
Mercado inmobiliario y orden residencial metropolitano en Bogotá
}

Óscar A. Alfonso. Universidad Externado de Colombia, Bogotá, Colombia.

RESUMEN | Las actuales mayores necesidades residenciales metropolitanas se han suscitado principalmente por la modificación de las relaciones de parentesco, que han dado lugar a un aumento en las jefaturas de hogar y la consecuente contracción del tamaño promedio de los hogares. Junto con el avance de las políticas de desalarización de la economía metropolitana, el mercado inmobiliario de la residencia nueva en Bogotá produce un incremento en el stock que no atiende satisfactoriamente los dos grandes desafíos que representan la densificación urbana y la producción de un orden residencial metropolitano menos segregado. El ajuste espacial del mercado formal se apoya tanto en la reducción de las áreas residenciales para hogares de bajos ingresos como en su localización periférica, lo que implica mayor hacinamiento y más altos costos de transporte para sus miembros.

PALABRAS CLAVE $\mid$ mercado inmobiliario, metropolización, localización.

ABSTRACT | The increase in metropolitan residential needs has arisen mainly from changing family relationships resulting in an increase in household headships and the ensuing contraction of their average size. Amid the advancement of "desalarization" labor policies in the metropolitan economy, the housing market of new residences in Bogotá has produced an increase in the residential stock that does not cover sufficiently the major challenges presented by urban densification, and by the production of a less segregated metropolitan residential order. The formal market's spatial adjustment is based both on the reduction of residential areas for low-income households, and their peripheral location, which implies an increase in overcrowding and transportation costs for their members.

KEY WORDS | real estate market, metropolization, location.

Recibido el 26 de enero de 2010, aprobado el 7 de noviembre de 2011

E-mail: oscar.alfonso@uexternado.edu.co

Este artículo es resultado de la investigación sobre Competitividad del sector inmobiliario residencial. Agradezco a Melba Rubiano, Lilián Buitrago, Carlos Alonso y Humberto Molina los aportes intelectuales para su elaboración. 


\section{Introducción}

La forma de operación del mercado inmobiliario residencial formal y sus resultados socioespaciales en la producción de cierto orden residencial es una cuestión de trascendencia social; su análisis, sin embargo, ha sido opacado por el énfasis dado al colapso financiero hipotecario en los países centrales y sus secuelas para la crisis económica global. Los vínculos entre la economía monetaria del mercado hipotecario y la economía espacial de la localización residencial se establecen al calor de la valorización y desvalorización de vecindarios en aquellas metrópolis que refuerzan sus vínculos con los municipios de su área de influencia inmediata. Tal es el caso de Bogotá en relación con la Sabana de Bogotá.

La forma de operación mencionada guarda relación con el devenir de un Estado corporativista en el que el sistema de intermediación de intereses de grupos no competitivos se opone a las aspiraciones pluralistas de un modelo democrático (Schmitter, 1974, pp. 93-94). Los presidentes de los gremios privados agencian querellas contra el Estado y la regulación urbanística, y luego se posicionan como ministros del ramo. El Poder Ejecutivo promueve marcos institucionales como el que comenzó a operar desde 1991 con la elevación a rango constitucional de los principios del ordenamiento territorial, continuó en 1997 con la expedición de la Ley 388 que los desarrolló, y avanza en la actualidad con la adopción y/o revisión de los planes de ordenamiento territorial, fase última en la que se torna más notoria que antes la incidencia de los gremios inmobiliarios en las reglamentaciones nacionales y locales.

La cuestión residencial metropolitana alcanza contornos sociales y políticos de mayor alcance que las meras tipologías de ocupación. La residencia es empleada por las familias de los segmentos de ingresos muy elevados como símbolo de su prestigio. La ostentación se torna así un vehículo para transmitir al resto de la sociedad una supuesta superioridad cultural, lo que comporta la apropiación de ciertos lugares del medio metropolitano por familias interesadas en la producción de barreras a la entrada de otras familias de ingresos inferiores. Qué tipo de activo residencial producir, en qué lugar de la estructura residencial metropolitana hacerlo y para quién hacerlo es la ecuación a la que se enfrentan los agentes inmobiliarios $y$, al resolverla, se encaminan a producir un nuevo orden residencial o a ratificar el existente. El resultado es la segmentación del mercado inmobiliario residencial, esto es, la edificación de vecindarios arreglados para alojar familias relativamente homogéneas, pero bastante diferenciadas de las que residen en otros vecindarios. La impronta de tal opción es una metrópoli segregada con un bajo patrón de sociabilidad y la emergencia de incentivos para la relocalización residencial en la búsqueda de externalidades de vecindad (Abramo, 2011b, p. 182).

Las reacciones en cadena originan la desvalorización virtual de ciertos vecindarios, fenómeno que señala el inicio del colapso de convenciones metropolitanas débiles y anuncia la crisis. Esta última es apalancada, además, por el inadecuado funcionamiento de los eslabonamientos anteriores y posteriores. Tal visión pesi- 
mista de la forma de operación del mercado inmobiliario residencial implica la regulación y políticas urbanas como mecanismos alternativos de coordinación de las elecciones individuales de localización, diferentes a la "mano invisible descontrolada” (Fujita, Krugman \& Venables, 2000, p. 31), que conducirá el sistema a reiterados colapsos.

\section{Liberalización, mercado y sistema de precios}

La libre operación de los mercados inmobiliarios residenciales se soporta en sofisticados modelos cuya síntesis (Fujita, 1989) proclama la consecución de los mejores logros sociales a partir de la conciliación, nada fácil, entre la libertad de elección de localización residencial y la realización de un orden residencial estable y eficiente, en un marco de equilibrio general (cfr. Abramo, 2011a). En ese tipo de modelos, la segregación residencial es tanto resultado como punto de partida, en la medida en que es el ingreso familiar el que permite realizar las mejores ofertas por las localizaciones que ofrece el mercado inmobiliario residencial. Pero tal segregación no puede considerarse como un gran logro social y, de hecho, justifica la regulación en búsqueda de mejores resultados socioespaciales.

La idea de la libre operación del mercado inmobiliario y sus logros a través de las operaciones de coordinación de una "mano invisible" metropolitana se ha desarrollado a la par de la de un Estado mínimo, que se limita a garantizar los derechos de propiedad como fin que encarna el bien común, concepciones arraigadas en el pensamiento y en el discurso de aquellos reformadores contemporáneos que creen que la economía de hoy es tan simple como la de 1776. La del presente ha alcanzado un enorme grado de complejidad, producto de la existencia de grandes capitales en busca de valorización, de la maduración del proceso de urbanización de la población y de cotidianas innovaciones lanzadas al mercado, todo lo cual requiere de un Estado solvente que esté en capacidad de controlar y regular a unos pocos para ampliar la libertad de las mayorías. El propósito de elevar la competitividad del aparato productivo se formuló como el segundo fin de un nuevo orden económico basado en la reducción de los costos de las firmas que operan en mercados oligopólicos, siendo la desalarización de la economía el costo social en que se ha incurrido para alcanzar tal propósito.

La persistencia y fortalecimiento de las barreras a la entrada de los mercados oligopólicos ha triunfado en la disputa teórica entablada con la hipótesis de que las elevadas ganancias sectoriales son incentivo suficiente para promover la competencia. Las guerras de precios y los acuerdos colusorios se imponen en el sistema de precios que, como en el caso de los inmobiliarios, no son ni de equilibrio ni de competencia. El optimismo diferido al largo plazo, en el que se supone que las barreras a la competencia cederán a su impulso en un ambiente desregulado, es exagerado y la intervención en busca de mejores logros económicos y sociales no da espera, pues - como en el estudio que nos ocupa - la incidencia de las reformas liberalizadoras de la economía en el orden residencial metropolitano ha sido segregadora. 
Iniciadas en 1990 con la Reforma Laboral que impuso la flexibilización del contrato de trabajo, ese conjunto de reformas liberalizadoras mencionadas modificó el curso de la moneda, creando desajustes irreparables a la demanda interna de las economías metropolitanas. Además, la flexibilización del contrato laboral deterioró la calidad del trabajo, ocasionando un incremento abrupto en los movimientos cotidianos de los residentes en las metrópolis. Como consecuencia, se elevaron la congestión vehicular y las emisiones metropolitanas de $\mathrm{CO}_{2} \mathrm{y}$, con ello, se contrajo la productividad laboral en el núcleo metropolitano, debido al incremento en el tiempo medio de viaje entre el lugar de residencia, el sitio de trabajo y los demás destinos cotidianos.

Con la escasa transparencia de la tasa de interés en un ambiente de evidente opacidad del sistema financiero hipotecario, operó una reforma unilateral al contrato de hipoteca, que desató una insólita despatrimonialización de un número considerable de familias. La desconfianza en la estabilidad de las reglas pactadas en los contratos laborales y de hipotecas ha ocasionado la contracción de la recurrencia de agentes al mercado. La audacia del capital inmobiliario para enfrentar esos entrabes a su valorización ha cristalizado en la consolidación de las fiducias como nueva forma de organización de la producción, la financiación y la circulación de los activos residenciales, mecanismo restricto a las familias solventes con capacidad de ahorro. Corolario de lo anterior - y sus manifestaciones más duraderas - son la consolidación de una metrópoli de inquilinos como alternativa al estrangulamiento gradual del mercado inmobiliario residencial, y la profundización de la segregación socioespacial.

Por lo demás, el pretendido objetivo de incrementar la competitividad no se alcanzará por estas vías, habiéndose creado un ámbito metropolitano propicio para la consolidación del poder de mercado de ciertos oligopolios cuya existencia constriñe la libertad de elección de la inmensa mayoría de los residentes en las metrópolis colombianas, las que ahora se encuentran ad portas de otras reformas ultraliberalizadoras.

\section{Desafíos metropolitanos, oligopolios y poder de mercado del sector inmobiliario}

Enfrentar la inseguridad y modernizar el sistema de transporte masivo son las cuestiones hacia las que los poderes públicos han dirigido su intervención e intentado orientar la opinión ciudadana en los últimos años. Mientras que el incremento en el pie de fuerza de la policía es el medio escogido para intentar contener el crimen, las inversiones en el sistema Transmilenio se juzgan insuficientes para una metrópoli de 7,3 millones de habitantes, los cuales realizan cotidianamente extensos movimientos característicos de una economía laboral metropolitana flexibilizada e informalizada. La realización de la Primera Línea del Metro es incierta, pues, aun con la garantía de la Nación de comprometer vigencias presupuestales futuras para apalancar la operación financiera del proyecto, su costo se desconoce, como también el nivel de la tarifa. La discusión sobre el trayecto se ha banalizado y, no obstante, ha 
logrado opacar otras discusiones cruciales, como la del número de estaciones y sus áreas aferentes y la tecnología que se empleará. Esas decisiones son cruciales, pues, además del esfuerzo fiscal adicional para los residentes, una tarifa más elevada que la del actual sistema promoverá la densificación, mientras que una más baja posibilitará nuevas localizaciones residenciales en las periferias.

En términos de la producción de un nuevo orden residencial metropolitano, la densificación o la dispersión residencial es la gran disyuntiva que enfrenta Bogotá. Como efecto combinado del crecimiento poblacional anual de alrededor de 105.000 residentes nuevos en la ciudad, y de las modificaciones en las relaciones de parentesco que da lugar a la formación de 81.000 hogares cada año, el stock residencial se debería incrementar en 1.140 .165 unidades en los próximos quince años: 282.678 unidades para subsanar el déficit residencial de 2005 y 857.487 para atender la demanda residencial de los hogares recién formados. La alternativa de la densificación implica incrementar la actual, que es de 46,3 viviendas por hectárea, hasta 70 viviendas por hectárea. La alternativa de la dispersión comporta el incremento de la incidencia migratoria popular de Bogotá sobre Soacha y la sustitución de áreas rurales por usos residenciales suburbanos para hogares solventes en los municipios del occidente y del norte de la Sabana de Bogotá, proceso que en la actualidad se realiza con una densidad de dos viviendas por hectárea.

El mercado residencial metropolitano y sus eslabonamientos operan al margen de esos desafíos, pues sus estructuras son oligopólicas y, por tanto, el poder de mercado de las firmas que allí funcionan se emplea para imponer un margen de ganancia a la demanda que es compatible con la reafirmación de un orden residencial metropolitano segregado. Los eslabonamientos anteriores al inmobiliario residencial son los mercados del suelo, de materiales de construcción y de trabajo, ya que son sus soportes espaciales, materiales y humanos; los eslabonamientos posteriores, en tanto, son los mercados financieros hipotecario y fiduciario y el de la publicidad inmobiliaria, en razón a que los capitales allí involucrados requieren de la existencia de los activos residenciales para su valorización.

Para analizar el poder de mercado de las firmas que operan en esos ámbitos se emplea el índice de Herfindahl, "que es la suma del cuadrado de las participaciones de las empresas en el mercado” (Call \& Holahan, 1985, p. 389). Se trata de un índice cuyo rango alcanza el valor de la unidad en el caso de un monopolio y en el límite inferior es igual a $1 / \mathrm{n}$, en donde $n$ es "el número de empresas en una industria compuesta de empresas con la misma participación”, siendo "mayor mientras más desigual sean las participaciones” (Call \& Holahan, 1985, p. 390). En los demás mercados, el índice es muy elevado si se tiene en cuenta que, por ejemplo, la fusión entre dos empresas cerveceras de los Estados Unidos haría pasar el índice de 0,1644 a 0,1766 , incremento de 0,0118 , juzgado sustancial por el Departamento de Justicia que bloqueó dicha fusión (Call \& Holahan, 1985, pp. 390-391).

En el mercado de materiales estructurales de construcción, el del acero en bajos perfiles y el del cemento son los de mayor trascendencia en la estructura de costos de la producción residencial. La estructura del mercado del cemento que se presen- 
ta en el Cuadro 1 es la prevaleciente después de una guerra de precios que terminó con la absorción de una firma indisciplinada, que le planteó competencia en los submercados populares a las tres firmas dominantes. Estas últimas y sus directivos fueron objeto de sanciones irrisorias por prácticas colusorias contra la competencia por parte de la Superintendencia de Industria y Comercio.

CUADRo 1 | Evolución del poder de mercado en la industria del cemento, Colombia, 2005-2009 (Índice de Herfindahl)

\begin{tabular}{l|c|c|c|c|c}
\hline \multirow{2}{*}{ FIRMAS } & \multicolumn{5}{|c}{ PARTICIPACIÓN (\%) } \\
\cline { 2 - 6 } & 2005 & 2006 & 2007 & 2008 & 2009 \\
\cline { 2 - 6 } ARgos & 0,623 & 0,623 & 0,623 & 0,611 & 0,654 \\
CEMEX & 0,272 & 0,272 & 0,272 & 0,267 & 0,237 \\
HOLCIM & 0,103 & 0,103 & 0,103 & 0,100 & $0,08,9$ \\
ÓNDICE DE HERFINDAHL & 0,473 & 0,473 & 0,473 & 0,455 & 0,492 \\
\hline
\end{tabular}

FUente Cálculos del autor con base en estadísticas del Instituto Colombiano de Productores de Cemento (ICPC).

Cementos Andino ingresó al mercado en 1998 y ya en 2005 había capturado una participación del $8 \%$ del mercado nacional, con una estrategia de precios más bajos que los de la competencia, dirigida hacia el segmento de la autoconstrucción. Precisamente en esa última etapa de Cementos Andino, el precio del cemento pasó de US\$11 a US\$3 por bulto de 50 kilos. La guerra promovida por las otras tres cementeras -Cemex, de México; Holcim, de Suiza; y Argos, de propiedad del Sindicato Antioqueño- implicaron una contracción anual de sus flujos de caja que bordearon los US\$200 millones (cfr. Ramírez, 2009). Esa firma indisciplinada - Cementos Andino - pasó a ser propiedad de Argos hacia finales de 2005 y, un mes después, el precio se elevó a US\$6, hasta situarse nuevamente en US\$11 poco después. Las multas de la Superintendencia de Industria y Comercio por prácticas contra la competencia ascendieron a cerca de US\$1,4 millones. Esas multas seguramente fueron conmemoradas por los cuadros directivos de las firmas sobrevivientes, pues, en efecto, solo representan el 0,72 del flujo de caja restaurado después de la exclusión de la firma indisciplinada.

Hacia 2008 se previó la entrada al mercado de una firma con una capacidad instalada de 300.000 toneladas, siendo su efecto una reducción del poder de mercado de las existentes. Dicho intento fue contenido con una reacción de la firma dominante, 
que en 2009 previó incrementar en un millón de toneladas la capacidad instalada en una de sus plantas, con lo que exacerbaba su poder de mercado. El precio que se está pagando por la desregulación de tales mercados oligopólicos es la inoperancia de la política nacional del subsidio a la vivienda de interés prioritario, pues, junto con el devenir de los precios del suelo, torna paulatinamente inviable su producción.

La trayectoria reciente y las diferencias de nivel de los precios del suelo urbano para uso residencial por segmentos de ingresos en Bogotá se presentan en la Figura 1, de la que es posible inferir su persistente diferenciación de los precios del suelo y, con ella, la ampliación de la segregación residencial.

Los precios de los activos residenciales son un fenómeno local, en este caso de escala metropolitana, pues los niveles alcanzados aquí pueden considerarse normales en otras metrópolis (cfr. Himmelberg, Mayer \& Sinai, 2005, p. 17). El grado de competencia entre los diferentes segmentos del mercado inmobiliario residencial también puede ser diferente entre metrópolis. La estimación de los indicadores de concentración del Cuadro 2 se realizó a partir de un recorte temporal y una actualización de la base estadística de la investigación de Rubiano (2007), que desde 1950 detectó 4.980 lanzamientos residenciales. Y junto con una información parcial del Observatorio de la Estructuración Residencial y la Ocupación y de la firma La Galería Inmobiliaria, suministrada por la Alcaldía Mayor de Bogotá en el marco de la "Misión Hábitat por Bogotá: Inclusión y derecho a la ciudad", se configuró una base ampliada con cerca de 2.900 lanzamientos inmobiliarios residenciales realizados por 1.030 agentes inmobiliarios metropolitanos entre 2006 y 2009.

FIGURA 1 | Evolución del precio real del suelo urbano para uso residencial por segmentos de ingresos, Bogotá, 1970-2003 ( $\$$ colombianos de 2003 por $\mathrm{m}^{2}$ )

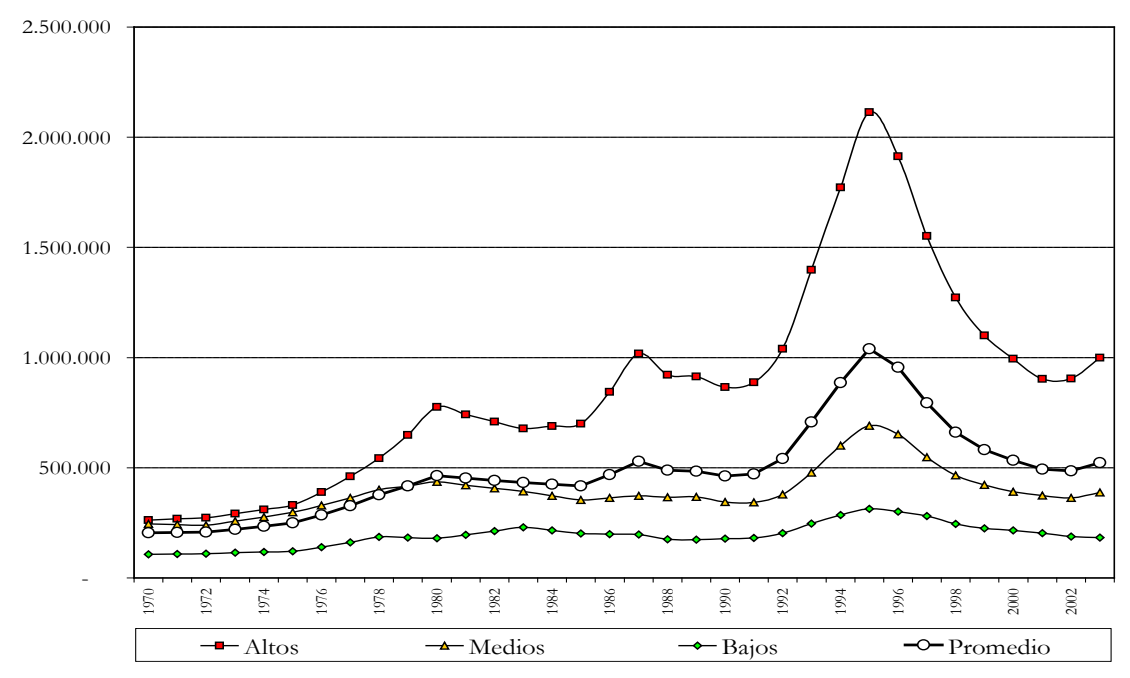

FUENTE JARAMillo (2005). 
CUADRO 2 | Características de la oferta y poder de mercado por segmentos del mercado inmobiliario residencial en la zona metropolitana de Bogotá, 2006-2009

\begin{tabular}{|c|c|c|c|c|c|}
\hline \multirow{2}{*}{ SEGMENTO } & \multicolumn{2}{|c|}{ ÁREA PROMEDIO $\left(\mathrm{M}^{2}\right)$} & \multicolumn{2}{|c|}{$\begin{array}{l}\text { PRECIO PROMEDIO } \\
\text { (US\$ DE 2009) }\end{array}$} & \multirow{2}{*}{$\begin{array}{l}\text { ÍNDICE } \\
\text { HERFINDAHL }\end{array}$} \\
\hline & Apartamento & Casa & Apartamento & Casa & \\
\hline $1 \mathrm{VIP}$ & 45,2 & 48,7 & 13.358 & 12.166 & 0,070839 \\
\hline 2 VIS & 52,6 & 63,1 & 23.688 & 21.528 & 0,055832 \\
\hline 3 & 87,6 & 125,2 & 89.912 & 82.463 & 0,016895 \\
\hline 4 & 137,2 & 220,9 & 201.441 & 211.017 & 0,018171 \\
\hline 5 & 203,7 & 269,9 & 335.826 & 330.564 & 0,067640 \\
\hline 6 & 250,7 & 329,7 & 474.991 & 462.813 & 0,053519 \\
\hline 7 & 308,9 & 356,0 & 589.290 & 583.826 & 0,101818 \\
\hline 8 & 335,3 & 331,6 & 707.029 & 708.935 & 0,117355 \\
\hline 9 & 332,6 & & 841.302 & & 0,251446 \\
\hline 10 & 348,8 & 496,0 & 1.054 .482 & 978.207 & 0,310596 \\
\hline TOTAL & & & & & 0,028548 \\
\hline
\end{tabular}

Fuente CÁlCulos con base en estadísticas de Rubiano (2007), La Galería Inmobiliaria (2007), y el ObserVATORIO DE LA ESTRUCTURACIÓN RESIDENCIAL Y LA OCUPACIÓN (OBRERO).

NOTA VIP = Vivienda de INTERÉs Prioritario; VIS = Vivienda de INTERÉs Social.

La competencia es mayor en el tercer segmento. Las diez primeras firmas con mayor poder de mercado producen el 40,4\% del stock residencial nuevo y el 99,8\% de su producción se focaliza hacia los primeros cinco segmentos. La concentración del mercado inmobiliario residencial se eleva en los segmentos superiores, a partir del séptimo, que son aquellos donde las diferenciaciones por áreas, precios y localizaciones son más conspicuas y donde, por tanto, se forjan los principales rasgos de la segregación residencial metropolitana. Adviértase que hay diferencias estadísticas sustanciales entre las áreas residenciales y los precios que, además, se incrementan a medida que el segmento de demanda al que se dirigen los hogares que buscan un lugar en la estructura residencial metropolitana es más solvente, siendo esos los criterios diferenciadores que, junto con la localización, inciden de manera decisiva en la segmentación del mercado inmobiliario residencial metropolitano y en la segregación socioespacial.

El coeficiente de Gini de la oferta residencial en Bogotá es de 59,1\%. Asumiendo que la oferta residencial está correlacionada positivamente con la distribución del ingreso, la ciudad soporta una pésima distribución. Cuando se incorpora la oferta residencial de la Sabana de Bogotá, el coeficiente de la oferta residencial metropolitana se contrae levemente, situándose en $57,1 \%$, fenómeno que ocurre principalmente por la incidencia de la oferta residencial para los segmentos de bajos ingresos en Soacha. Por su parte, el coeficiente de la oferta residencial en altura asciende a $64,7 \%$, que es reflejo del sesgo antidemocrático de la manera como se está verticalizando la metrópoli. 
La actividad inmobiliaria ostenta excedentes brutos de explotación del 28,7\%, superiores al excedente medio de la economía metropolitana, que es del 27,5\%, pero obviamente inferiores al de las actividades más lucrativas, como los servicios de salud de mercado, cuyo excedente anual alcanza el 63,8\% del valor bruto de la producción. Sin embargo, una porción relevante de las ganancias inmobiliarias que no se contabilizan en la Matriz Insumo-Producto son las plusvalías urbanas originadas en la intervención del Estado y que se distribuyen entre los propietarios del dominio sobre el suelo y los agentes inmobiliarios metropolitanos, de manera que, de contabilizarse la plusvalía, tal excedente se aproxima al nivel del de los servicios mercantes de salud.

Por su parte, el mercado financiero hipotecario opera en condiciones oligopólicas, al decir del Índice Herfindahl de 0,236763. La estructura de mercado de este eslabonamiento posterior, que se esboza en el Cuadro 3, revela que la valorización del capital financiero hipotecario depende, en especial, de la adquisición de la residencia por las familias de los segmentos de ingresos muy bajos y bajos. Tal importancia va decreciendo a medida que se pasa a un segmento superior, de lo que se deduce que el potencial de las fiducias en las que se ampara la producción residencial "sobre planos" se encuentra reservado para las familias solventes.

El desafío metropolitano de la producción residencial, la disyuntiva que enfrenta y las contradicciones del sistema, difícilmente podrán resolverse con un mercado segmentado, atrapado entre eslabonamientos que operan en condiciones cuasi monopólicas y oligopólicas y que, de hecho, se ha encaminado hacia un paulatino estrangulamiento, que se discute a continuación.

CUADro 3 | Profundización del crédito hipotecario y poder de mercado en la zona metropolitana de Bogotá, 2006-2009

\begin{tabular}{l|c|c}
\hline \multirow{2}{*}{ SEGMENTO } & $\begin{array}{l}\text { PORCENTAJE DE LA OFERTA } \\
\text { FINANCIADA CON CRÉDITO } \\
\text { HIPOTECARIO }\end{array}$ & ÍNDICE HERFINDAHL \\
\hline 1 VIP & 89,3 & 0,270594 \\
2 VIS & 88,1 & 0,239997 \\
3 & 79,5 & 0,226791 \\
4 & 59,6 & 0,267334 \\
5 & 36,5 & 0,290707 \\
6 & 36,8 & 0,418169 \\
7 & 22,4 & 0,882813 \\
8 & 6,0 & 1,000000 \\
9 & - & - \\
10 & 9,2 & 1,000000 \\
\hline TOTAL & 82,6 & 0,236763 \\
\hline
\end{tabular}

Fuente Cálculos con base en estadísticas de Rubiano (2007), La Galería Inmobiliaria (2007), y el OBSERVATORIO de la ESTRUCTURACIÓN RESIDENCIAL y la OCUPACión (OBRERo). NOTA VIP = VIVIENDA DE INTERÉS PRIORITARIO; VIS = VIVIENDA DE INTERÉs SOCIAL. 


\section{Estrangulamiento del mercado residencial metropolitano}

Las familias recurren a cuatro fuentes de recursos para la adquisición de una residencia nueva: la enajenación de una residencia usada cuando ella se posea, el crédito hipotecario, los ahorros de la familia y los subsidios del Estado para los segmentos 1 y 2. Estos últimos operan solo para las familias que no son propietarias.

Las familias enajenan la residencia usada debido a la penuria económica por la que atraviesan o por las posibilidades que las otras tres fuentes les abren para acceder a mejores vecindarios o a mayores áreas privadas. A los agentes inmobiliarios metropolitanos les interesa que el stock de la residencia usada en propiedad rote, pues de allí proviene una porción relevante de la solvencia exigida para comprar los activos residenciales nuevos. Algunas investigaciones dan cuenta de la notable estabilidad de las familias pobres - y aun de generaciones de ellas - en la misma residencia (Gilbert, 2001). En otras se sugiere la existencia de un mercado residencial popular muy dinámico (Abramo, 2011c, p. 293).

En la Figura 2 se presenta el precio promedio de la residencia y una estimación de la rotación de la residencia en propiedad para quintiles de ingresos bajo y medio bajo, calculado como el cociente entre las familias que cambiaron de residencia en propiedad en el último año y el total de las familias pertenecientes a cada quintil del gasto. La estadística empleada, la Encuesta de Calidad de Vida, no capta información sobre las familias de ingresos medios altos, altos y muy altos, como tampoco sobre las de ingresos muy bajos, donde la informalidad urbanística es más intensa.

El índice de rotación en este caso es de 3,3\%. La primera razón para esa bajísima cifra es la inaceptable sanción ejercida por el mercado residencial metropolitano. Si una familia promedio del primer quintil decide lanzar al mercado su residencia, fijaría un precio de US\$21.636, pero se encuentra con que el precio de oferta se encuentra $\$ 8.278$ por debajo de sus aspiraciones, forzando la sanción del mercado a que opte por abstenerse de la transacción. En el quintil siguiente la situación es semejante, aunque de menor calado: US\$1.398. Adviértase que aun alcanzado el precio promedio de US\$57.881, ninguna familia puede localizarse en algún vecindario del tercer segmento cuyos precios promedio oscilen entre US\$82.463 y US\$89.912.

La segunda razón de tan baja rotación es la escasa colocación del crédito hipotecario en esos segmentos. ¿Cuáles son las razones para que los bancos no consideren los activos residenciales de los pobres como garantía real de los créditos hipotecarios? En primer lugar, no los consideran garantía real porque los catalogan de activos riesgosos; pero, principalmente, no los consideran tales precisamente porque, si lo hicieran, se incrementaría la probabilidad de activar economías de vecindad y producir una depreciación virtual del stock residencial de los demás segmentos de mercado. Esto es, facilitarían que las familias pobres pudieran acceder a mejores vecindarios. Por tanto, los bancos hipotecarios operan con precaución al otorgar los créditos hipotecarios, en vista de que al validar una elección de localización de las familias, pueden originar la depreciación ficticia de activos residenciales cuya adquisición había sido amparada con sus créditos. Con ello, emerge el desbalance entre el monto de las deudas, la depresión 
del precio de mercado de los activos residenciales, y la responsabilidad del sistema financiero hipotecario en las reacciones en cadena residenciales que anteceden a las crisis económicas contemporáneas.

FIGURA 2 | Precio de la residencia e índice de rotación anual del stock inmobiliario residencial en propiedad por quintiles de gasto de las familias, Bogotá, 2007 (US\$ de 2009)

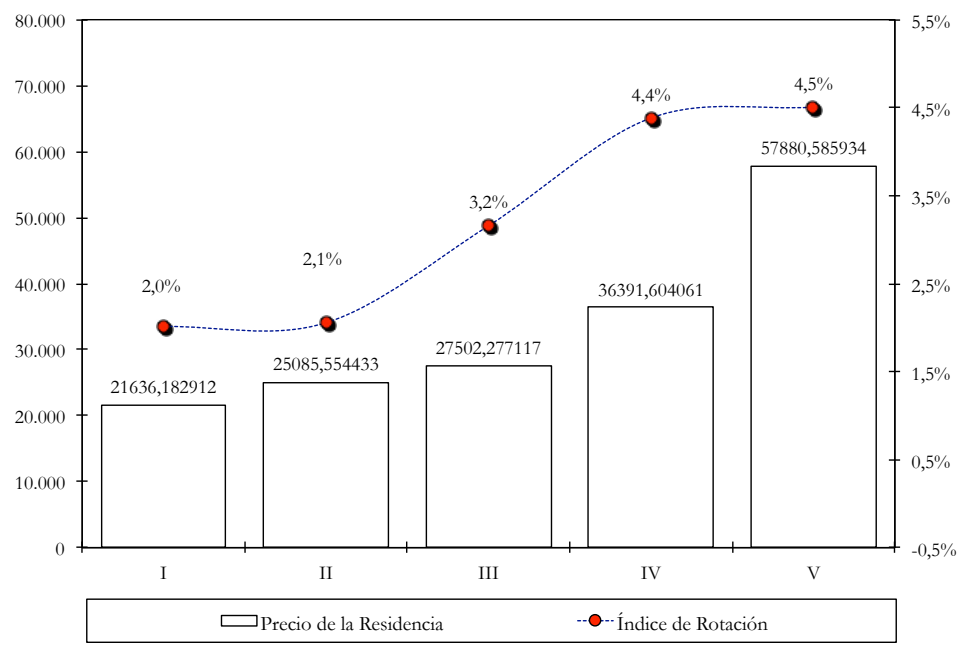

fuente Cálculos del autor con base en Encuesta de Calidad de Vida (ECV), 2007.

La crisis hipotecaria que se desencadenó desde mediados de los noventa tuvo su origen, por una parte, en la decisión unilateral de la autoridad monetaria de modificar la tasa de interés que, en los contratos de hipoteca del sistema UPAC (Unidad de Poder Adquisitivo Constante), estaba ligada a la inflación por la tasa de interés DTF (Depósitos a Término Fijo); y por otra, se originó en la innovación financiera de las Corporaciones de Ahorro y Vivienda, que idearon la cuota supermínima a través de la cual colocaron cantidades crecientes de crédito hipotecario. Es lo que el mal sentido común denomina como "burbuja crediticia". Cuando por efecto de la modificación de la autoridad monetaria la cuota supermínima se incrementó, así como los saldos insolutos hipotecarios, sobrevino la crisis que se ha pagado con la entrega en dación en pago a los bancos hipotecarios de cerca de 60.000 residencias de familias hoy despatrimonializadas.

El cambio unilateral en la regla de indexación pactada en el contrato de hipoteca detonó la morosidad en el pago de las cuotas periódicas, especialmente en el tramo de las familias que habían accedido al crédito hipotecario bajo la modalidad de amortización conocida como la "cuota supermínima", que era la menos onerosa de las 90 que ofrecían los operadores del sistema UPAC antes de 1999. La ampliación desregulada del acceso al crédito hipotecario y el afán de "prestar" de los bancos 
hipotecarios activó la búsqueda de las economías de vecindad. La mayor densidad de entregas en dación en pago correspondió a familias que entraron en desgracia al elevarse los gastos soportables por el paso de la inflación moderada a la volátil DTF, y ocurrió alrededor del prestigioso vecindario de La Carolina, proximidades de la carrera 15 con calle 127, en el norte de la ciudad. Los bancos hipotecarios, además, se reservaron la potestad de recibir tales bienes de manera discrecional. Posteriormente entró en vigencia el Decreto 2331 de 1998, con el que se limitó tal discrecionalidad, dando lugar a la aparición de efectos colaterales: nuevos vecindarios del centro, sur y suroccidente de la ciudad experimentaron el pánico de la salida de familias morosas. Pese a ello, esos bienes residenciales tuvieron una recuperación en su precio, la cual, sin embargo, no alcanzó a cubrir el monto al que habían llegado sus deudas.

En la actualidad, las colocaciones nominales del sistema UPAC/UVR (Unidad de Poder Adquisitivo Constante/Unidad de Valor Real) alcanzan montos semejantes a los de 1996. La desconfianza del público en la estabilidad de las condiciones pactadas en los contratos de hipoteca comienza a diluirse diez años después, al decir de las tendencias que se presentan en la Figura 3, en la que, sin embargo, también se evidencia el inicio de un nuevo período de contracción del crédito hipotecario. En el intertanto, entidades hipotecarias del Estado se han consolidado y otras del sector solidario han emergido para suplir parcialmente los requerimientos de crédito en segmentos que el sistema UPAC/UVR ya no cubre.

La desconfianza del público en la estabilidad de las condiciones pactadas en el contrato de hipoteca ha sido sustituida por la confianza que las familias solventes depositan en los agentes inmobiliarios metropolitanos a través del mecanismo de la fiducia. Esta consiste en un negocio financiero-inmobiliario en el que un agente inmobiliario garantiza la venta de un activo residencial con la existencia de un terreno para edificarlo y una licencia de construcción. Las familias, por su parte, depositan periódicamente una suma — su ahorro - en una fiducia previamente elegida por el agente inmobiliario en un banco, imputable al precio del activo residencial que aún no se ha comenzado a construir. Cuando el agente inmobiliario considera que el proyecto ha alcanzado el punto de equilibrio financiero, comienza a construir y, por tanto, las fechas pactadas para la entrega de la residencia son inciertas.

Esos segmentos que el mercado financiero hipotecario no cubre están conformados por un número creciente de familias cuyo nivel de ingresos es muy bajo, y errática la periodicidad del pago de los salarios, rasgos definitorios de un mercado laboral flexibilizado y de una economía con tendencias a la desalarización. Como proxy de esos resultados de las reformas laborales de inicios de los noventa, nótese en la Figura 4 la pérdida persistente de la participación de los pagos laborales en el valor agregado industrial que, en el caso de la industria localizada en la zona metropolitana de Bogotá, ha sido de $8,9 \%$ en los últimos quince años, mientras que en el resto de Colombia el fenómeno se ha presentado aún más agudo, pues tal pérdida asciende a 13,6\%. El deterioro en la calidad del empleo y la informalización laboral han sido la respuesta del mercado a las reformas liberalizadoras, siendo ese un marco en el cual es cada vez más difícil incrementar la tasa de ahorro de las familias - la llave con que se abren las puertas de los bancos hipotecarios-. 
FIGURA 3 | Tasa de crecimiento de los saldos reales del sistema UPAC/UVR (diferencia de logaritmos, precios de 1999)

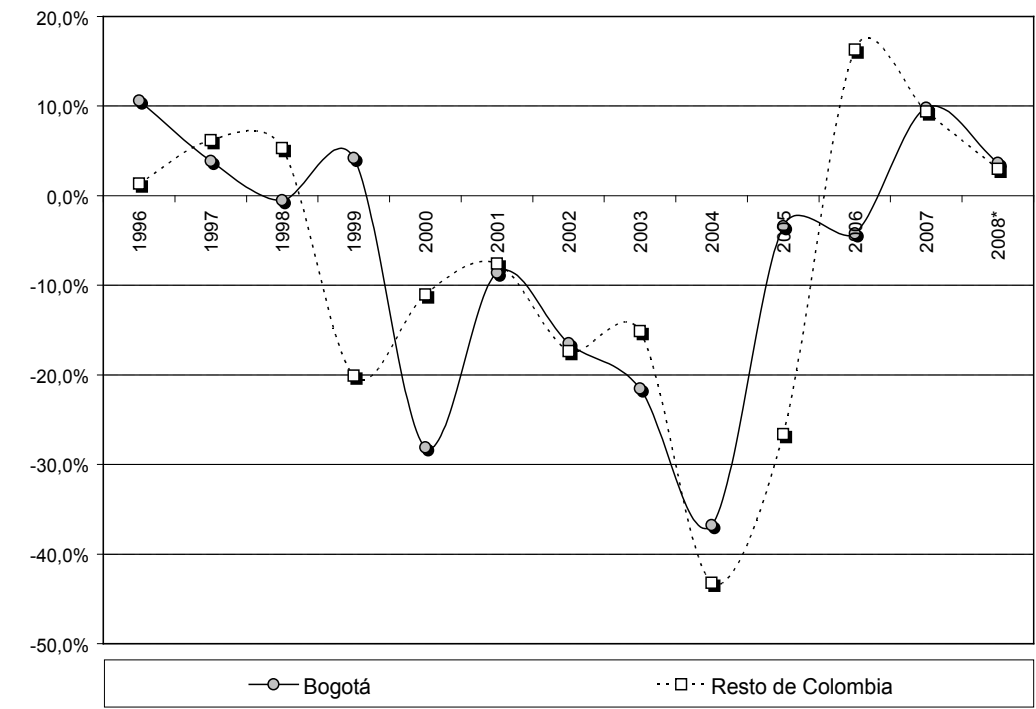

FUENTE Construida CON base en estadísticas de la Superintendencia Bancaria, La Superintendencia Financiera y el Departamento Administrativo Nacional de Estadística (DANE)

NOTA LOS SALdoS EN Bogotá PARA LOS ÚlTimos TRES AÑOS SE ESTIMARON CON BASE EN PROMEDIOS MÓVILES DE SEIS AÑOS.

FIGURA 4 | Participación de los pagos laborales en el valor agregado industrial, Colombia y Zona Metropolitana de Bogotá, 1985-2009 (porcentajes)

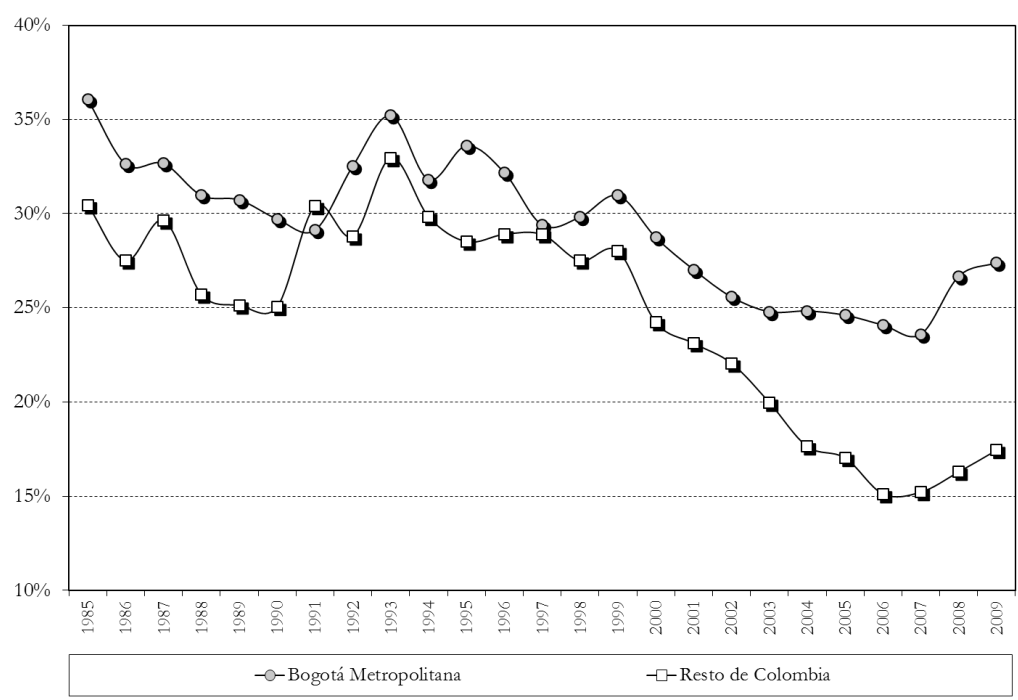

Fuente Cálculos del autor con base en la Encuesta Anual Manufacturera del Departamento AdmiNistrativo Nacional de Estadística (DANE). 
La desalarización de la economía ocasiona que una porción creciente del stock residencial nuevo se produzca para el alquiler y, con ello, la aspiración conservadora de las sociedades de propietarios, inspirada en el decimonónico atavismo a la propiedad, enfrenta limitaciones estructurales. La proporción de familias que residían en arriendo o en subarriendo en 2007 alcanzaba al 43,8\% de las residentes en Bogotá, la cual, por tanto, tiende a consolidarse como una ciudad de inquilinos.

La política nacional de subsidios directos para la adquisición de la residencia es un paliativo para un problema de mayor envergadura. El subsidio es un instrumento que ha entrado en una fase de inoperancia, puesto que, al nivel que han alcanzado los precios del suelo para familias de bajos ingresos, y el costo de los materiales de construcción, la producción de una residencia solo es viable a partir de 87,5 salarios mínimos legales. En ese rango — esto es, a un precio de US\$22.319-, esa vivienda no es accesible para las familias con ingresos mensuales de US\$255 o de interés prioritario, a no ser que se produzca con un área irrisoria, que teóricamente oscila entre 23 y $45 \mathrm{~m}^{2}$ (Alfonso, 2009, p. 6). En 2009 fueron lanzados siete proyectos residenciales para este segmento, cuyas áreas privadas oscilan entre $36 \mathrm{y} 49 \mathrm{~m}^{2}$.

\section{El orden residencial metropolitano y las contradicciones en curso}

La disyuntiva que enfrenta Bogotá para encarar el desafío de la producción y el orden residencial comporta contradicciones que el mercado inmobiliario tiende a resolver de la forma menos deseada. Siendo la opción de la verticalización/densificación de la ciudad socialmente deseable, a la manera como se está alcanzando le es inmanente una pésima distribución que acentúa la mala distribución del ingreso que ya soporta. La otra opción, que es la expansión/dispersión hacia la Sabana de Bogotá, implica mejores posibilidades de acceso a una residencia para las familias de todos los segmentos, pero le es igualmente inmanente un encarecimiento generalizado de la intervención pública y de la vida en la metrópoli, y una pérdida del potencial de productividad del trabajo, correlativo a los mayores tiempos de desplazamiento cotidiano de los residentes en la zona metropolitana.

Esa dialéctica del orden residencial metropolitano se acentúa a medida que el mercado inmobiliario avanza libremente hacia su estrangulamiento, debido a que en ese trayecto los ajustes más trascendentes del sistema de precios involucran a las familias de los segmentos inferiores y medios. Siendo así, estos hogares se inhiben de recurrir al mercado de la residencia nueva, optando por la ocupación en alquiler cuando ello es soportable, o por la informalidad urbana cuando tal opción no se encuentra a su alcance.

La producción residencial formal en una metrópoli en desarrollo como Bogotá reafirma el esquema general de segregación socioespacial en construcción desde 1950, consistente en que las familias de los segmentos de ingresos medios altos, altos y muy altos se aglutinan en vecindarios nobles del norte y nororiente de la ciudad, mientras que las zonas centrales y centrooccidentales están reservadas para los hogares de los segmentos de ingresos medios, y el sur lo está para los de ingresos ba- 
jos y muy bajos. Buena parte de las zonas periféricas de la ciudad son ocupadas por la urbanización popular que, sin embargo, no accede al suelo ambientalmente más valorizado y con mayor capacidad portante de los Cerros Orientales de la ciudad.

El precio residencial por metro cuadrado más elevado se produce en la calle 93 con carrera 9 en la zona de El Chicó (véase la letra P en la Figura 9) y se cotiza a US $\$ 3.535 / \mathrm{m}^{2}$, y el más barato es de US $\$ 150 / \mathrm{m}^{2}$ y se localiza en la calle 105 sur con carrera 71 en la localidad de Bosa, colindante con el municipio de Soacha. En la Figura 5 se presenta la distribución espacial de los precios residenciales de la oferta reciente en el núcleo metropolitano, distribución en la que se ha tomado precisamente la mencionada zona de El Chicó como centroide de las operaciones inmobiliarias de los agentes inmobiliarios metropolitanos, que las han dirigido hacia el sur y hacia el norte de la calle 93, tal como se presentan en la Figura 5.

FIGURA 5 | Precios promedio de la oferta residencial, Bogotá 2006-2009 (US\$ por $\mathrm{m}^{2}$ )

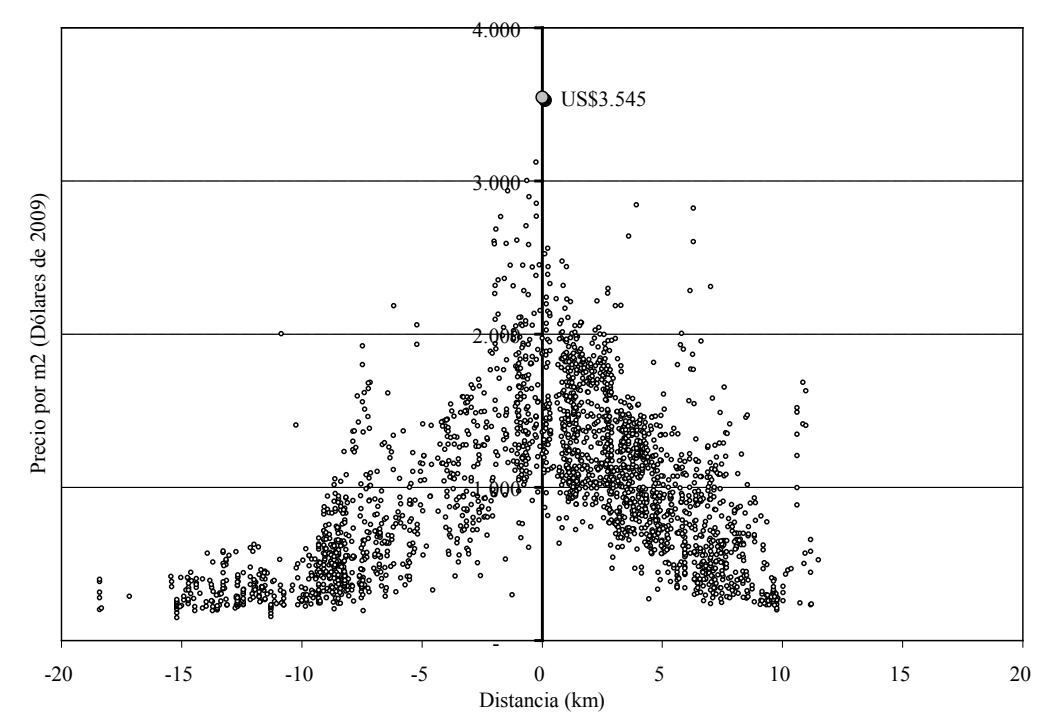

FUente Construida con base en estadísticas de Rubiano (2007), La Galería Inmobiliaria (2007), y el Observatorio de la Estructuración Residencial y la Ocupación (Obrero).

Para estimar los gradientes de precios unitarios residenciales en relación con la distancia, se empleó un modelo exponencial. ${ }^{1}$ Esa distancia se estimó como el valor de la hipotenusa de un triángulo cuyos catetos - calles y carreras - se suponen de una longitud uniforme de 80 metros, método conocido como "la distancia recorrida a vuelo de pájaro". Un procedimiento semejante se empleó con las áreas

1 El modelo estimado sugiere la hipótesis de que los precios se comportan a la manera de una función exponencial negativa del tipo $\mathrm{P}_{\mathrm{r}}=\mathrm{P}_{0} \mathrm{e}^{\mathrm{br}}$, en donde $P_{\text {r }}$, son los precios observados a una distancia $r$ del centroide, $P_{0}$ es el precio en el centroide, $e$ es la base del logaritmo natural y $-b$ es el gradiente de precios (Richardson, 1986, p. 212). Para estudiar en detalle la versión más sofisticada de esa hipótesis, véase Fujita (1989). 
residenciales promedio que se presentan en la Figura 6, siendo la más elevada la que se detectó en la calle 131 con carrera 5 en el sector de Multicentro (véase la letra A en el Figura 9) y la más baja en la calle 146 con carrera 95 en la localidad de Suba.

FIGURA 6 | Áreas promedio de la oferta residencial, Bogotá 2006-2009 $\left(\mathrm{m}^{2}\right)$

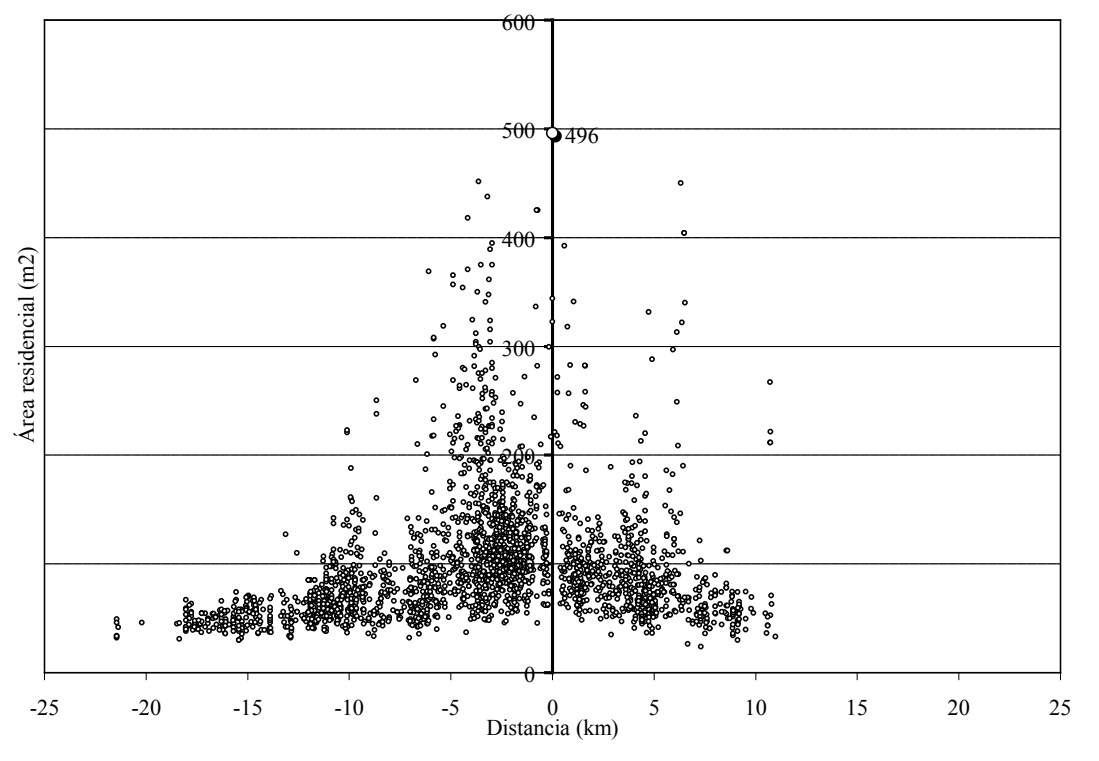

FUente Construida con base en estadísticas de Rubiano (2007), La Galería Inmobiliaria (2007), y el Observatorio de la Estructuración Residencial y la OCupación (Obrero).

El precio más elevado no coincide con la localización del área más elevada, fenómeno que revela la existencia de poderosos elementos diferenciadores/segregacionistas del espacio residencial, los cuales no son captados por el influyente pensamiento espacial conservador (Richardson, 1986; Fujita, 1989). Más aún, para el pensamiento espacial neoclásico, la contracción en el gradiente de precios (renta) es compensada con la ampliación en el área residencial disponible (tamaño del terreno). A partir de ahí, se describe un orden residencial único, estable y eficiente, surgido del equilibrio espacial en el que cualquier movimiento en la localización residencial es compensado con un movimiento de signo contrario en los costos de transporte, disyuntiva que reposa en un proceso cognitivo de valoración del tiempo de las personas. Las funciones de utilidad homogéneas son el inicio de una manera elegante de sostener que, alcanzado ese equilibrio, las familias no tienen incentivos para relocalizarse y, por tanto, ese equilibrio es un óptimo espacial paretiano.

Los resultados de estimación que se presentan en el Cuadro 4 comprueban todo lo contrario. Primero, que el ajuste espacial de mercado tiene el mismo signo, de manera que la contracción en el gradiente de precios se acompaña indefectiblemente de un movimiento semejante en las áreas ofrecidas. Y, segundo, que la contrac- 
ción en las áreas residenciales es más que proporcional a la reducción en los precios con la distancia a los centroides identificados.

CUADRO 4 | Resultados de estimación de los gradientes de precios y áreas de la oferta residencial nueva, Bogotá, 2006-2009

\begin{tabular}{|c|c|c|c|c|}
\hline & \multicolumn{2}{|c|}{ HACIA EL SUR } & \multicolumn{2}{|c|}{ HACIA EL NORTE } \\
\hline & Precios & Áreas & Precios & Áreas \\
\hline GRADIENTE & $-0,0093$ & $-0,0668$ & $-0,0127$ & $-0,06093$ \\
\hline PROBABILIDAD & $<0,01$ & $<0,01$ & $<0,01$ & $<0,01$ \\
\hline $\mathrm{R}^{2}$ & 0,488117 & 0,408133 & 0,337843 & 0,12358 \\
\hline $\mathrm{N}$ & 1.048 & 1.797 & 1.471 & 722 \\
\hline
\end{tabular}

Fuente Cálculos con base en estadísticas de Rubiano (2007), La Galería Inmobiliaria (2007), y el ObSERVATORIO DE LA ESTRUCTURACIÓN RESIDENCIAL y LA OCUPACIÓN (OBRERo).

El orden residencial en curso se presenta de manera simplificada en la Figura 7. De cara a los desafíos metropolitanos, es posible inferir que la forma de operación segmentada del mercado inmobiliario residencial no los encara, pues, de una parte, las diferencias estadísticas en las áreas residenciales son considerables; y de la otra, son los segmentos de los hogares de bajísimos ingresos — de la vivienda de interés prioritario y de la vivienda de interés social — los únicos solidarios con la necesidad de la densificación residencial. La densidad del tercer segmento es semejante a la densidad promedio de la ciudad. Del cuarto segmento en adelante, los aportes a la densificación son muy bajos, aproximándose a cero. Se infiere, entonces, que la forma de operación del mercado inmobiliario residencial acentúa la segregación y realiza un uso ineficiente del suelo urbano construible.

Reconocido el aporte de los hogares de muy bajos ingresos al desafío de la densificación residencial, la contracción en el área residencial está correlacionada positivamente con la inadecuada dotación de la accesibilidad metropolitana y de los medios para transportarse, situación que agrava la penuria localizacional de las familias que residen en las periferias de la metrópoli. El tiempo promedio simple empleado en el traslado del lugar de residencia al sitio de trabajo es de 88,5 minutos. Cuando se pondera por la frecuencia de uso de los diferentes medios, ese tiempo es de 68,6 minutos. Asumiendo que tal tiempo de desplazamiento es improductivo y tedioso, en promedio cada bogotano ve ampliada irremediablemente su jornada de trabajo en $28,6 \%$ o, de manera equivalente, dispone de 2 horas y 17 minutos diarios menos para la reposición de su fuerza de trabajo. 
FIGURA 7 | Densidades residenciales adicionales y área residencial promedio por segmento de mercado, Bogotá, 2006-2009

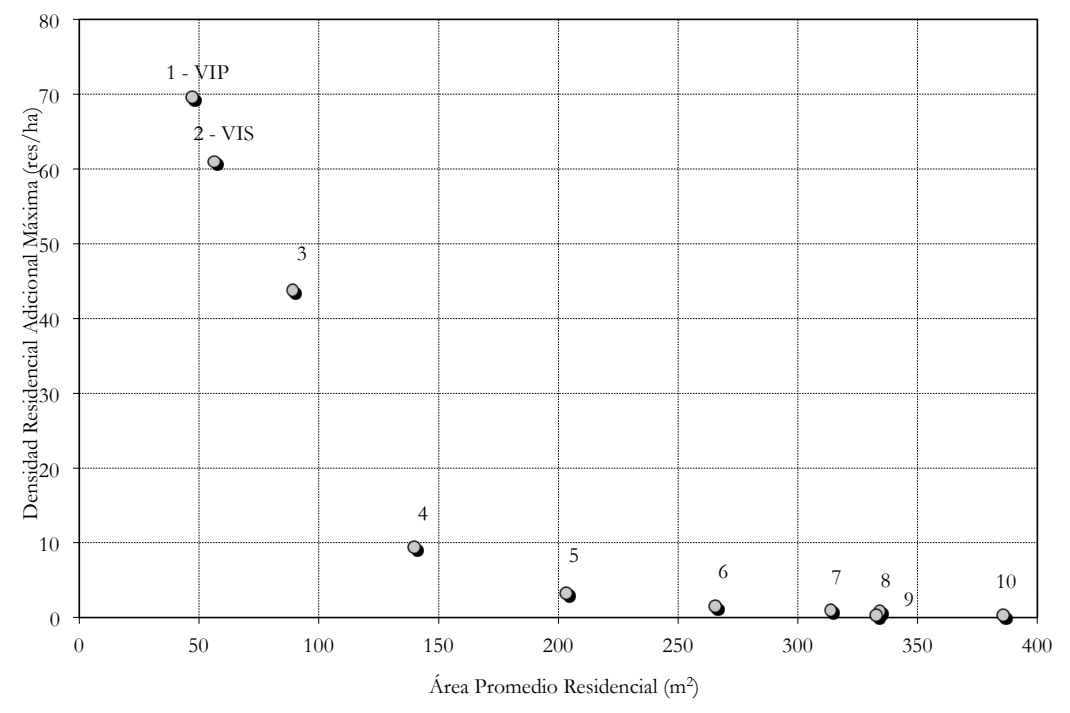

Fuente Construida con base en estadísticas de Rubiano (2007), La Galería Inmobiliaria (2007), y el OBSERVATORIO de la ESTRUCTURACIÓN RESIDENCIAL y la OCUPACIÓN (OBRERo).

Los trabajadores que se desplazan a caballo, en bicicleta (otro medio), a pie, en taxi y en bus intermunicipal gastan más tiempo que los que se transportan en los otros medios. El transporte organizado por las empresas se encuentra muy próximo al nivel del promedio de la ciudad y, de allí hacia abajo, todos los medios empleados son ahorradores de tiempo de viaje. Nótese, sin embargo, que ese transporte de la empresa es el usado con menos frecuencia, mientras que las motocicletas son usadas con mayor frecuencia y el tiempo de desplazamiento es menor. La proliferación de motocicletas en los medios metropolitanos obedece a la necesidad de movilización de los trabajadores con contrato flexible vinculados a la distribución y a la mensajería.

La disputa del mercado del transporte colectivo, según se infiere de la Figura 8, está entablada entre el bus urbano, que es usado por el 57,2\% de los bogotanos que se movilizan en la ciudad para llegar a su trabajo, el automóvil particular (10,9\%) y el Transmilenio (11,0\%), pero la diferencia está en la longitud de los trayectos que se realizan. Mientras que la duración del trayecto medio de Transmilenio, de 46,4 minutos, permite recorrer cerca de 20 kilómetros, incluyendo al menos un tramo de ruta alimentadora, en ese mismo lapso un bus urbano podría recorrer cerca de 9 kilómetros y el automóvil particular, alrededor de 1,4 kilómetros. Por tanto, la modernización del transporte colectivo y su masificación posibilitan nuevas localizaciones y, por consiguiente, imprimen cierto dinamismo al mercado inmobiliario residencial. 
FIGURA 8 | Tiempo de desplazamiento entre el lugar de residencia y el sitio de trabajo por medio de transporte, Bogotá Metropolitana, 2007

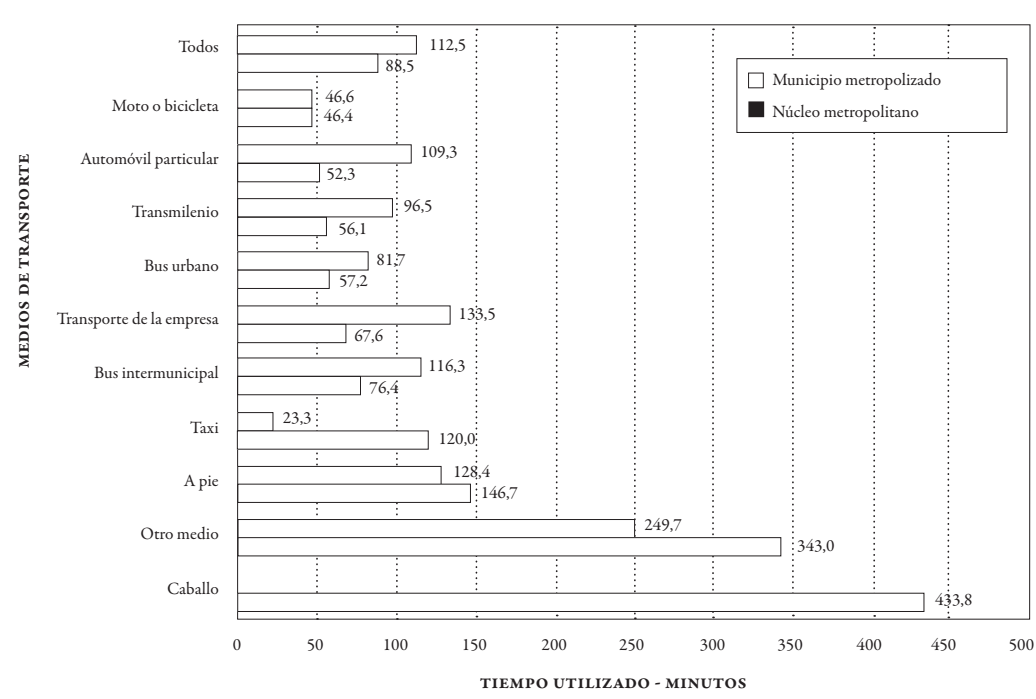

FUente Cálculos del aUtor con base en estadísticas del Departamento Administrativo NaCional de EsTADÍSTICA (DANE).

Por otra parte, entre Bogotá y la zona metropolitana circundante se realizan cotidianamente alrededor de 141.863 viajes por motivos laborales (Alfonso, 2009, p. 83). El tiempo medio de viaje se incrementa en $27,1 \%$, equivalente a 48 minutos de recorrido en ambos sentidos. En el caso del transporte intermunicipal y el automóvil particular, el tiempo medio prácticamente se duplica, mientras que la proporción del incremento en el tiempo medio de viaje es un tanto menor cuando se emplea el bus urbano (42,9\%), el bus intermunicipal (52,2\%) y el Transmilenio (72,0\%).

Conocidos los tiempos promedios de viaje y las alternativas para realizarlos, así como la proximidad a otras familias de ingresos similares o superiores y a los bienes públicos metropolitanos, las familias encuentran ventajas al cambiarse de residencia, las cuales se captan como externalidades monetizables de la elección de localización residencial. Ese potencial, sin embargo, es inhibido por los factores que explican la tendencia secular al estrangulamiento del mercado inmobiliario residencial.

\section{La coyuntura 2009-2011, antecedentes y perspectivas}

La crisis económica mundial que se desató en 2009 tuvo su origen en la aceleración de los mecanismos de valorización del capital inmobiliario y financiero en los Estados Unidos, fenómeno inexplicable para el pensamiento conservador, que acostumbra diluir tales mecanismos en el sentido común de la "burbuja" inmobiliaria o hipotecaria. 
Colombia atravesó por una crisis semejante diez años atrás por causa de la desinstitucionalización de la regulación financiera, que se manifestó en la opacidad del sistema hipotecario de valor constante. Sus administradores emitieron señales que estimularon el sobreendeudamiento de familias, las cuales, al acentuarse la modificación unilateral de las condiciones pactadas en los contratos de hipoteca por la Junta Directiva del Banco de la República e incrementarse el valor de la UPAC por encima del máximo legal, se vieron inmersas en la cesación de pagos y en el crecimiento abrupto de los saldos insolutos hipotecarios. En los vecindarios que habían recibido a las familias cuya solvencia había sido creada artificialmente por el sistema hipotecario, se presentaron reacciones en cadena que aceleraron la depreciación virtual de los activos residenciales, incrementándose las entregas de las residencias en dación en pago a las entidades del sistema financiero hipotecario. Tales entidades las aceptaban de manera selectiva, privilegiando las localizadas en los vecindarios nobles, hasta que en 1999 la ley acabó con tal práctica. Pero en esa misma coyuntura 1998-1999, Bogotá asistió al lanzamiento de un gran proyecto urbano - la Primera Línea del Metro (PLM) -, realizado con el apalancamiento financiero del nivel central de gobierno. Con su publicación se desató un proceso de anticipaciones que tornó aún más turbulento el mercado inmobiliario residencial, proceso que un año después se agudizó con la declaratoria de insuficiencia financiera del gobierno central y la adopción de un sistema integral de transporte masivo de diferente trazado y menos oneroso, el Transmilenio.

La coyuntura 2009-2010 tiene algunas semejanzas con la de 1998-1999, salvo que la crisis no es autóctona, sino que sus efectos son importados de los países centrales. Las entregas en dación en pago continúan, pero a un ritmo menos desenfrenado que el de hace diez años, y se ha realizado un nuevo anuncio de la Primera Línea del Metro, cuyo costo no se conoce, como tampoco la tarifa al usuario, pero las autoridades locales celebran el apalancamiento financiero brindado al proyecto por el gobierno nacional. Aun sin esa información decisiva, circulan los discursos de los especuladores sobre la capacidad del anuncio de modificar los precios de los activos residenciales y, con ello, el potencial de que el proyecto cuente con la suficiencia financiera requerida. Los más avezados se atreven a divulgar resultados de ejercicios hipotéticos que sugieren que los mayores impactos no se sentirán en las áreas próximas a las estaciones de la PLM, sino en las que cubren las rutas alimentadoras.

Lo cierto es que, puesto que el costo de la PLM se desconoce, no es posible estimar la magnitud del esfuerzo fiscal que deberá realizar la administración de la ciudad y, por tanto, no son previsibles los reajustes en la destinación del presupuesto de inversión a la provisión de bienes públicos. En el mismo sentido, la tarifa al usuario tampoco se conoce, lo que torna imposible inferir si la PLM va a inducir la compactación/densificación o la expansión/dispersión de Bogotá.

El trazado de la PLM se presenta en el Figura 9, junto con la densificación residencial adicional que se deriva de la producción residencial para todos los segmentos del mercado. La mayor densidad residencial adicional es de 102 residencias por hectárea y se alcanza justo en los vecindarios propuestos para los hogares de muy bajos ingresos de los segmentos 1 y 2 , en las proximidades de El Tintal y Casablanca-Portal de las Américas. Es decir, es un acierto de la anticipación de los agentes inmobiliarios 
metropolitanos a la producción de la función pública de accesibilidad metropolitana. Sin embargo, otras zonas de elevada densificación popular, como las próximas a Bosa y al borde sur de la ciudad por la avenida Villavicencio, no se incorporan fácilmente al sistema de transporte masivo propuesto, situación que es aún más gravosa, en términos de costos y tiempos de viaje, para los residentes de los vecindarios populares de Suba en el noroccidente de Bogotá. La dispersión espacial de las familias del tercer segmento es la más elevada de todas, pero recientemente ellas han tendido a concentrarse entre Mazurén y Toberín, vecindarios localizados en las proximidades de la autopista Norte con calle 170. A medida que se avanza en el segmento, las zonas de Pontevedra (avenida Suba con calle 116) son cada vez menos atractivas para las familias de ingresos elevados y muy elevados, que tienden a agruparse desde Rosales (calle 72 con avenida Circunvalar), en dirección a El Chicó Reservado (calle 93 con carrera 9) hasta Multicentro (calle 127 con carrera 5).

A diferencia del trazado del fallido proyecto PLM de 1998, que cubría un tramo de movilidad popular de la zona occidente entre los barrios Garcés Navas y Quinta Camacho, el nuevo trazado luce como una PLM política, en el sentido de que el trayecto entre la estación calle 100 y la estación de San Victorino (17 en la Figura 9) facilita la accesibilidad/movilidad cotidiana de personas vinculadas al sector de los servicios de alta jerarquía, mientras que entre San Victorino y Portal de las Américas capta la demanda de movilidad cotidiana de personas vinculadas al trabajo informal y al formal de baja remuneración.

En el intertanto, la producción residencial en la zona metropolitana continúa preservando tres rasgos que la singularizan: i) la insuficiencia para atender el déficit total y la demanda por formación de nuevos hogares en Bogotá, que requiere alrededor de 76.000 unidades anuales, mientras que en el último lustro se están produciendo 42.300 en promedio anual; ii) la ineficacia de la política de mercado para atender la demanda insatisfecha de los hogares de bajos ingresos que, como se deduce de la Figura 10, es una porción marginal de la producción formal; y iii) la reproducción del esquema general de segregación residencial, pues el municipio de Soacha, conurbado de las localidades pobres del suroccidente de la ciudad, continúa acogiendo a los hogares de menores ingresos, mientras que en Chía se cierra el mercado residencial para hogares de esas características y se acoge de manera privilegiada la producción residencial para los hogares de estratos socioeconómicos altos.

Puesto que la mayor cantidad del stock residencial se está produciendo para los hogares que menos lo necesitan, es plausible pensar que en estos haya excesos de stock que acarrean, entre otras cosas, una prolongación en los períodos vacantes de la porción que se dedica al alquiler. En contraste, el déficit residencial de los hogares de bajos ingresos está siendo suplido por el incremento en la producción informal, cuyas particularidades aún están por ser exploradas, lo que seguirá ocurriendo mientras subsistan las brechas entre uno y otro mercado. En la actualidad, el precio de oferta del suelo y la vivienda precaria en los mercados informales del suroccidente de la ciudad asciende a US $\$ 29,5 / \mathrm{m}^{2}$, mientras que el más barato de la vivienda formal, el del segmento de la vivienda de interés prioritario, asciende a US $\$ 461 / \mathrm{m}^{2}$. 
FIGURA 9 | Orden residencial en curso y trazado de la Primera Línea Metro, Bogotá, 2006-2009

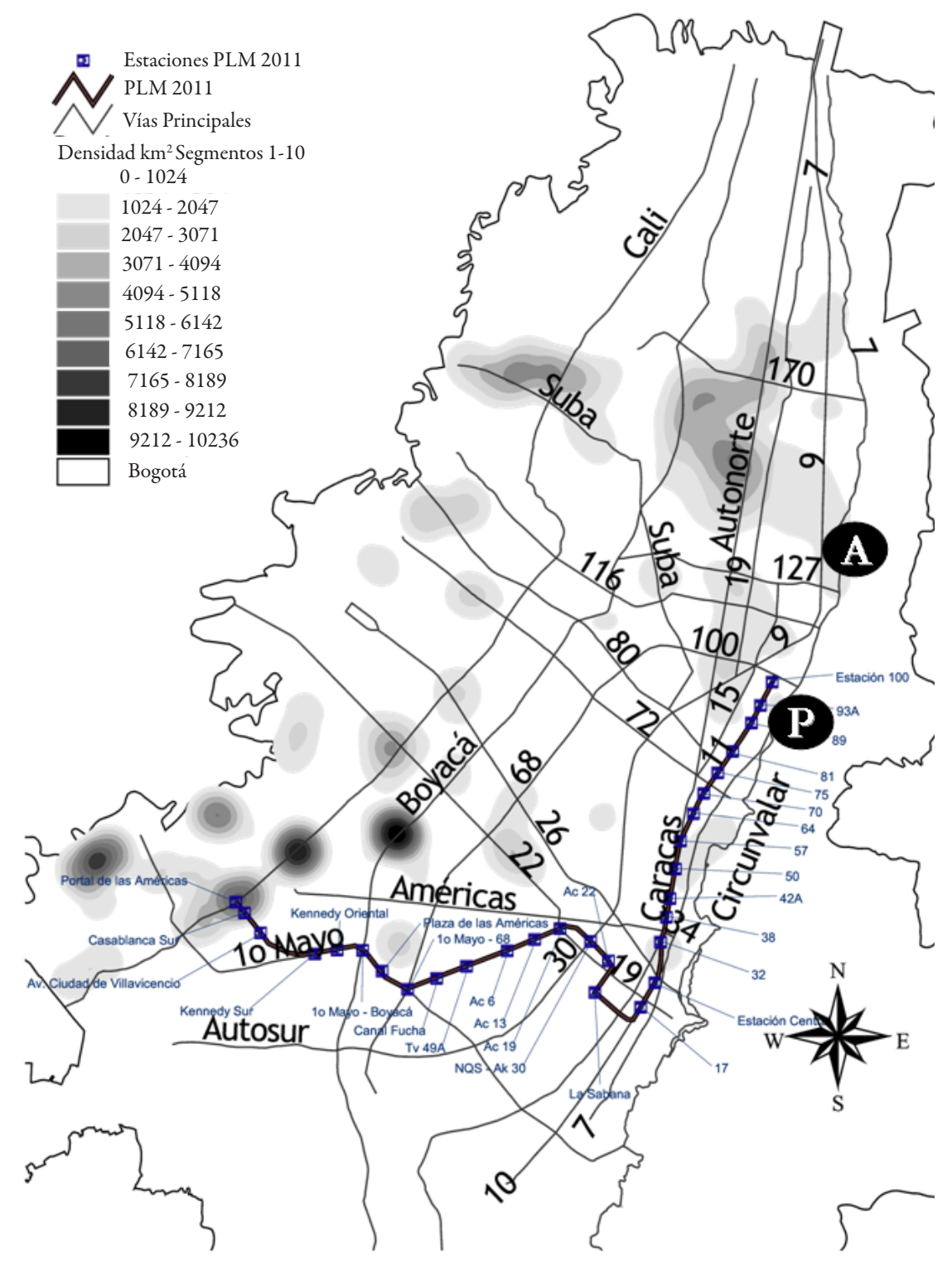

FUente Construido con base en estadísticas de Rubiano (2007), La Galería InMobiliaria (2007), y el Ob-

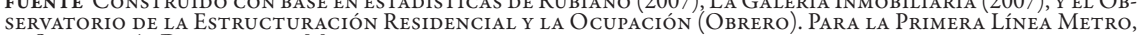
la Secretaría Distrital de Movilidad. 
FIGURA 10 | Estructura de la producción residencial formal $\left(\mathrm{m}^{2}\right)$ por estratos socioeconómicos en la zona metropolitana de Bogotá, 2006-2011
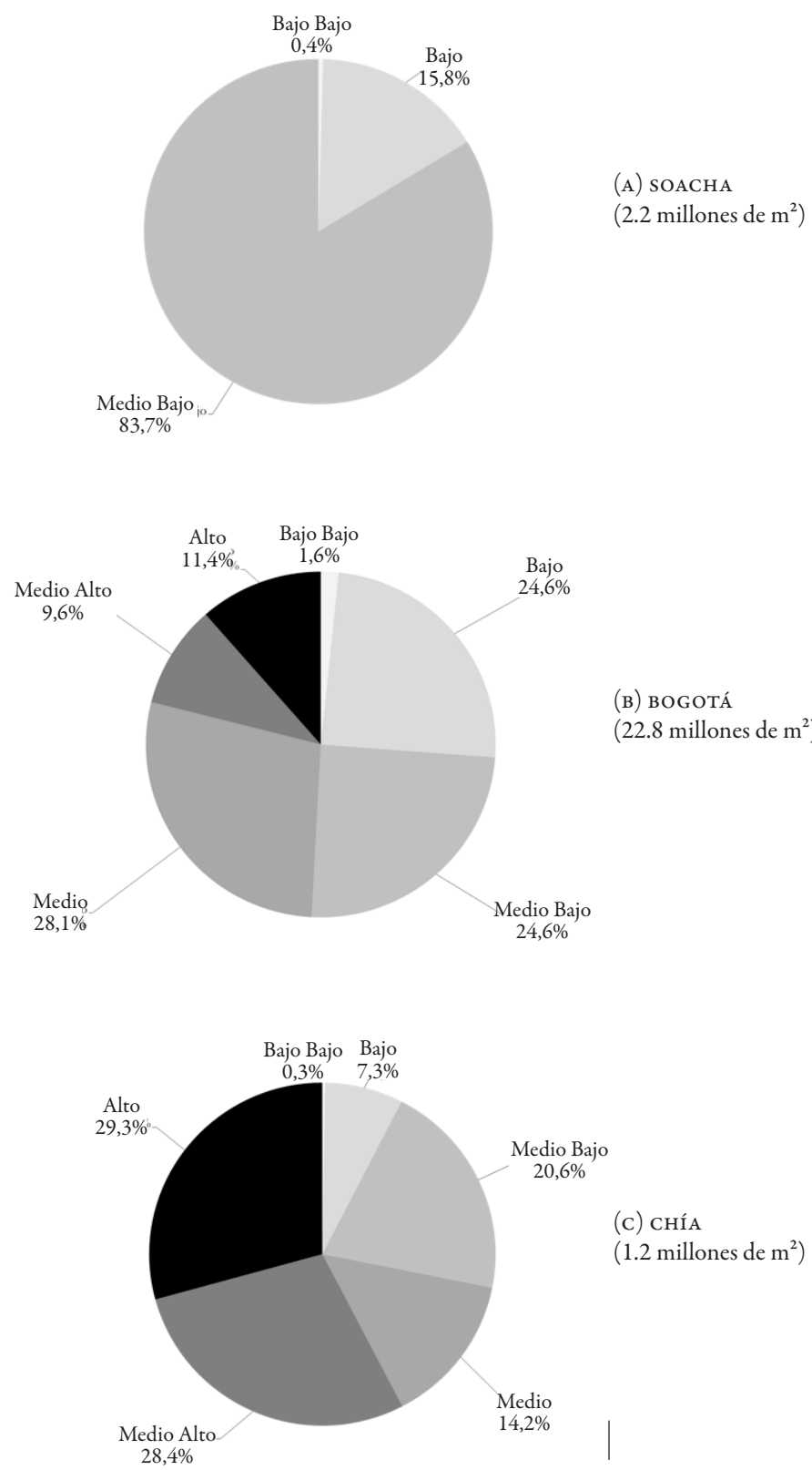

Fuente Cálculos del autor con base en estadísticas del Departamento Administrativo Nacional de ESTADÍSTICA (DANE). 


\section{Consideraciones finales}

La contradicción entre un núcleo metropolitano menos democrático, pero que exige menores esfuerzos colectivos, y una zona metropolitana que demanda mayores esfuerzos en la producción de bienes públicos, pero que es menos segregada, se ha originado en un ámbito institucional 'laissez-fairista' impuro caracterizado por la apropiación privada de los esfuerzos colectivos urbanos, en el que, ante la inoperancia de un Estado mínimo, una porción de la riqueza producida colectivamente va a parar a manos privadas. La liberalización de tales mercados oligopólicos produce resultados socialmente indeseables, cuya reparación exige mayores esfuerzos económicos. El ámbito para resolver la contradicción suscitada en la disyuntiva entre verticalización/densificación y expansión/dispersión residenciales, es el de la política residencial metropolitana, cuyo fin último es la elevación sustancial del patrón de vida, lo que implica la democratización de las condiciones de accesibilidad, habitabilidad y sociabilidad metropolitanas. El desafío concomitante es la producción de un nuevo orden residencial metropolitano incluyente, en el que se remueva la segregación residencial.

La administración Santos le ha asignado al sector de la construcción, junto a la minería, la mayor responsabilidad en la promoción del crecimiento económico. En el lenguaje gubernamental, es una locomotora que debe arrastrar la producción de un millón de viviendas como meta del cuatrienio, pero que, según se ha argumentado, arrastra dos pesados vagones - la industria del cemento y el mercado del suelo metropolitano- que tornan más lento su andar. Puesto que los mercados inmobiliarios residenciales son, fundamentalmente, un hecho metropolitano, las políticas basadas en los mecanismos de mercado ofrecen diferentes resultados socioespaciales. En el caso de la zona metropolitana de Bogotá, la reproducción del esquema general de segregación residencial y el incremento en el déficit residencial concentrado en las familias de bajos ingresos, en contraste con la sobreproducción de activos residenciales para hogares de elevados ingresos, son las señales más evidentes de la ceguera de la "mano invisible metropolitana".

\section{Referencias bibliográficas}

Abramo, O. (2011a). Mercado y orden urbano: del caos a la teoria de la localización residencia. Serie Economía Institucional Urbana, n. ${ }^{\circ}$ 2. Bogotá: Universidad Externado de Colombia.

Abramo, O. (2011b). La ciudad caleidoscópica, coordinación espacial y convención urbana: una perspectiva heterodoxa para la economía urbana. Serie Economía Institucional Urbana, n. ${ }^{\circ}$. Bogotá: Universidad Externado de Colombia.

Abramo, O. (2011c). La producción de las ciudades latinoamericanas: mercado inmobiliario y estructura urbana. Serie Textos Urbanos, n. ${ }^{\circ}$ 9. Quito: Organización Latinoamericana y del Caribe de Centros Históricos (Olacchi)/Municipio Metropolitano de Quito. 
Alfonso, Ó. (2009). Economía institucional de la ocupación del suelo en la Región Metropolitana de Bogotá. Documento de Trabajo, n. ${ }^{\circ}$ 28. Bogotá: Facultad de Economía de la Universidad Externado de Colombia.

Alfonso, Ó. \& Alonso, C. (2008). Características poblacionales de la provisión del agua potable en los municipios colombianos. Documento de investigación, n. ${ }^{\circ} 11$, Informe del estudio en profundidad en Colombia. Brasilia/Bogotá: Instituto de Pesquisa Econômica Aplicada (IPEA)/United Nations Population Fund (UNFPA), Proyecto RLA5P201: Soporte Regional a Población y Desarrollo en la Implementación de los Objetivos de Desarrollo del Milenio (ODM) en la Región de América Latina y el Caribe.

Call, S. T. \& Holahan, W. T. (1985). Microeconomía. México: Grupo Editorial Iberoamérica.

Carmona, F. \& Monroy, J. (2009). Crisis hipotecaria y orden residencial. Un análisis de las entregas en dación en pago, Bogotá 1996-2007. Trabajo de grado, Facultad de Economía, Universidad Externado de Colombia, Bogotá.

Commons, J. R. (1925). Law and Economics. The Yale Law Journal, 34(4), 371-382. Tomado de http://www.jstor.org/stable/788562, septiembre 3 de 2008.

Commons, J. R. (2003 [1931]). Economía institucional. Revista de Economia Institucional, 5(8), 191 201. Bogotá: Universidad Externado de Colombia.

Fujita, M. (1989). Urban Economic Theory. Land Use and City Size. Cambridge, MA: Cambridge University Press.

Fujita, M., Krugman, P. \& Venables, A. J. (2000). Economía espacial: las ciudades, las regiones y el comercio internacional. Barcelona: Editorial Ariel.

Gilbert, A. (2001). ¿Una casa es para siempre? Movilidad residencial y propiedad de la vivienda en los asentamientos autoproducidos. Revista Territorios, 6, 51-73. Bogotá: Universidad de Los Andes.

Himmelberg, Ch., Mayer, Ch. \& Sinai, T. (2005). Assessing high house prices. Bubbles, fundamentals, and misperceptions. Journal of Economic Perspectives, 19(4), 67-92.

Jaramillo, S. (2005). Observatorio del espacio construido en Bogotá. Bogotá: Centro de Estudios sobre Desarrollo Económico (CEDE), Facultad de Economía, Universidad de los Andes.

Richardson, H. W. (1986). Economía regional y urbana. Madrid: Alianza Editorial.

Rubiano, M. (2007). Lanzamientos inmobiliarios residenciales y estructuración intraurbana de Bogotá, 1950-2005. Tesis de Maestría en Planeamiento Urbano y Regional. Río de Janeiro, Instituto de Pesquisa y Planeamiento Urbano y Regional, Universidad Federal de Río de Janeiro (IPPUR/UFRJ).

Schmitter, Ph. (1974). Still the century of corporativism? The Review of Politics, 36(01), 85-131. doi: $10.1017 /$ S0034670500022178.

\section{Artículos de prensa}

Ramírez, V. A. (2009). El mercado del cemento en Colombia. Semanario Portafolio, marzo 3. 
